\title{
Effect of Different Concentrations of Esmolol on Perioperative Hemodynamics and Analgesia in Patients Undergoing Colectomy: A Prospective, Randomized Controlled Study
}

\author{
Fuxi Song (1D' \\ Yanwu Jin' \\ Peng Li' \\ Chao Zheng $\mathbb{I D}^{2}$ \\ Xin Zhao $\mathbb{D}^{\prime}$ \\ 'Department of Anesthesiology, The \\ Second Hospital, Cheeloo College of \\ Medicine, Shandong University, Jinan, \\ Shandong, People's Republic of China; \\ ${ }^{2}$ Department of Breast Surgery, The \\ Second Hospital, School of Medicine, \\ Cheeloo College of Medicine, Shandong \\ University, Jinan, Shandong, People's \\ Republic of China
}

Purpose: The aim of this study was to investigate the efficacy of esmolol on intraoperative hemodynamic and perioperative analgesic management.

Methods: Totally, 125 patients undergoing colectomy were randomly divided into three groups. Group S (saline group) was administered $0.75 \mathrm{~mL} / \mathrm{kg} / \mathrm{h}$ of normal saline for $5 \mathrm{~min}$ before anesthesia induction and maintenance of $0.25 \mathrm{~mL} / \mathrm{kg} / \mathrm{h}$; Group $\mathrm{E}_{1}$ and Group $\mathrm{E}_{2}$ were administered $0.5 \mathrm{mg} / \mathrm{kg}$ and $1.0 \mathrm{mg} / \mathrm{kg}$ esmolol for $5 \mathrm{~min}$ before anesthesia induction, and maintained of $0.5 \mathrm{mg} / \mathrm{kg} / \mathrm{h}$ and $2.0 \mathrm{mg} / \mathrm{kg} / \mathrm{h}$, respectively. Several parameters including indexes of hemodynamics variation (primary outcome), intra- and postoperative analgesic usage, and pain score were measured.

Results: Group $\mathrm{E}_{1}$ and Group $\mathrm{E}_{2}$ had significantly lower intubation response than Group $\mathrm{S}(\mathrm{P}=$ $0.007, \mathrm{P}=0.001)$, and extubation response of Group $\mathrm{E}_{2}$ was significantly lower than Group $\mathrm{S}(\mathrm{P}$ $=0.007)$. The opioid consumption in Group $\mathrm{E}_{1}$ and Group $\mathrm{E}_{2}$ was significantly lower than in Group $\mathrm{S}$ intraoperatively $(\mathrm{P}=0.020$ and 0.007$)$. The incidence of postoperative adverse reactions among the three groups was not statistically significant $(\mathrm{P}=0.368$ and 0.772$)$.

Conclusion: Esmolol $0.5 \mathrm{mg} / \mathrm{kg}$ and $1.0 \mathrm{mg} / \mathrm{kg}$ infusion before intubation both can effectively inhibit the intubation response, while only maintenance with $2.0 \mathrm{mg} / \mathrm{kg} / \mathrm{h}$ of esmolol can reduce the incidence of extubation response. At the same time, esmolol can decrease intraoperative opioid requirement without increasing the risk of adverse reactions.

Trial Registration: ChiCTR1900024538 and the date of registration was July 15, 2019 at http://www.chictr.org.cn.

Keywords: esmolol, hemodynamics, analgesia, intubation response, extubation response

\section{Introduction}

Surgical stress is a kind of non-specific defense reaction, which is mainly characterized by sympathetic excitation and enhancement of the hypothalamic-pituitary-adrenal axis (HPA or HTPA axis). ${ }^{1}$ For patients undergoing colectomy, a variety of reasons, especially tracheal intubation and extubation, can cause strong stress response, which leads to obvious hemodynamic instability and cardiovascular or cerebrovascular accidents, and brings great challenges for perioperative anesthesia and analgesia. ${ }^{2}$

Opioids are the mainstay of treatment for perioperative pain, but their administration increases the incidence of respiratory complications, slows down normal
Correspondence: Xin Zhao

Department of Anesthesiology, The Second Hospital, Cheeloo College of

Medicine, Shandong University, No. 247

Beiyuan Street, Jinan, Shandong, 250033,

People's Republic of China

Fax +86-53I-88962544

Email lujnzx@sohu.com 
gastrointestinal motility, and prolongs hospital stay. ${ }^{3,4}$ With the development of enhanced recovery after surgery (ERAS), reducing the use of opioids in perioperative period has become the common goal of anesthesiologists. The dosage of opioids should be strictly controlled whenever possible, which should not only meet the needs of analgesia perioperatively, but also minimize the incidence of adverse reactions. ${ }^{5}$ Due to various factors that cause the stress reaction in colectomy, such as intestinal traction, stimulation of nerves and baroreceptors caused by surgical or anaesthetic operation, it is unscientific to use opioids only inhibiting it. To seek corresponding auxiliary therapy inhibiting the stress response is crucial.

Esmolol is an ultra-short acting, cardio-selective $\beta_{1^{-}}$ adrenergic receptor blocker with the characteristics of quick onset, short half-value period, strong controllability, and rarely side effects, ${ }^{6}$ which is effective in blunting adrenergic responses to perioperative stimuli including the tracheal intubation, intraoperative events, and tracheal extubation. Previous clinical studies have demonstrated that perioperative infusion of esmolol reduced opioid consumption and stress response. ${ }^{7-9}$ However, in previous studies, the dosage of esmolol was used in a wide range. ${ }^{10}$ The meta-analysis results of Figueredo et al, ${ }^{11}$ which reported that the most effective method to inhibit adrenergic response to intubation was to use esmolol with loading dose of $500 \mathrm{ug} / \mathrm{kg} / \mathrm{min}$, followed by continuous infusion of $200-300 \mathrm{ug} / \mathrm{kg} / \mathrm{min}$. In the study of Ratnani et al, administration of $1.5 \mathrm{mg} / \mathrm{kg}$ esmolol 2 minutes before extubation could effectively inhibit hypertension and tachycardia. ${ }^{12}$ However, we have not found relevant reference supporting the influence of continuous intraoperative infusion of esmolol on extubation. Considering that our patients are relatively older, and many patients' basal heart rate is maintained between 60 and $70 \mathrm{bpm}$, the application safety range of esmolol is narrower than that of normal people. Esmolol is an ultra-short-acting $\beta$-blocker with a short duration of action for a single dose. Continuous administration can prolong the drug action of esmolol, at the same time, decrease the risk of bradycardia caused by a rapid single injection, which is often very dangerous for the elderly. Therefore, after fully consideration of the tolerance of patients and clinical experience of our anesthesiologists, we selected two relatively low doses to compare the effect of intraoperative esmolol administration on hemodynamics and perioperative analgesia for patients undergoing colectomy.

\section{Methods}

\section{Trial Design}

This study is a single center, prospective, randomized, controlled clinical trial conducted at The Second Hospital, Cheeloo College of Medicine, Shandong University, Jinan, Shandong, China, approved by the Ethics Committee of the Second Hospital of Shandong University with the approval number KYLL-2019(LW) 009 on June 10, 2019. The study was prospectively registered at http://www.chictr.org.cn on July 15, 2019, identifier ChiCTR1900024538.

\section{Participants}

One hundred and fifty-two consecutive patients with the age of 20-70 years old, American Society of Anesthesiologists (ASA) physical status I-III, undergoing selective colectomy for colon cancer were identified from July 20, 2019 to August 31, 2020. One hundred and thirtyeight were enrolled and randomly allocated into three groups using computer-generated randomization numbers contained in sealed opaque envelopes and 14 were excluded because of exclusion criteria; What is more, 4 patients were excluded due to occurring severe hemodynamic fluctuation; 9 patients were lost to follow-up; 125 patients were included in the final statistical analysis. Exclusion criteria were: patient refusal, pregnant, history of bradycardia or atrioventricular block; history of hypotension; history of bronchial asthma or severe chronic obstructive pulmonary disease (COPD); history of relevant allergy to related perioperative medications, patients with severe organ damage such as heart, hepatic and renal failure; body mass index (BMI) less than 18 or more than 30 $\mathrm{Kg} / \mathrm{m}^{2}$; patients who cannot cooperate with the trial. All the enrolled patients provided a written informed consent.

\section{Anesthesia and Analgesia Grouping}

All patients enrolled were divided into three groups according to the random number generated by computer. Before induction, Group S (saline group) were administered $0.75 \mathrm{~mL} / \mathrm{kg} / \mathrm{h}$ of normal saline for $5 \mathrm{~min}$ and maintenance of $0.25 \mathrm{~mL} / \mathrm{kg} / \mathrm{h}$; Group $\mathrm{E}_{1}$ and Group $\mathrm{E}_{2}$ were administered $0.5 \mathrm{mg} / \mathrm{kg}$ and $1.0 \mathrm{mg} / \mathrm{kg}$ for $5 \mathrm{~min}$, and maintenance of $0.5 \mathrm{mg} / \mathrm{kg} / \mathrm{h}$ and $2.0 \mathrm{mg} / \mathrm{kg} / \mathrm{h}$, respectively. Esmolol (2 mL: 0.2 g*2, Qilu Pharmaceutical Company, China) used in this trial was diluted with normal saline to 
$50 \mathrm{~mL}(8 \mathrm{mg} / \mathrm{mL})$. Saline and esmolol infusion stopped immediately upon extubation.

\section{Anesthesia Method}

After ASA standard monitors were applied, induction of general anesthesia was standardized in the three groups using propofol $(1.5 \sim 2.0 \mathrm{mg} / \mathrm{kg})$ and sufentanil $(0.3 \sim 0.5$ $\mu \mathrm{g} / \mathrm{kg}$ ). Endotracheal intubation was facilitated with cisatracurium $(0.2 \mathrm{mg} / \mathrm{kg})$. After induction, the radial arterial line and the catheterization of right internal jugular vein were given and ultrasound-guided quadratus lumborum block (US-QLB) was performed using $60 \mathrm{~mL}$ of $0.3 \%$ ropivacaine $(30 \mathrm{~mL}$ into each side). Sufentanil $0.1 \mathrm{ug} / \mathrm{kg}$ (could be reused 1 time if there was no adequate improvement in 10 minutes) would be given when the patient's MAP or HR exceeds $20 \%$ or more of their baseline value during surgical procedures such as skin dissection and intestinal traction. During the operation, vasoactive drugs (phenylephrine, ephedrine, nitroglycerin, urapidil, atropine, or isoprenaline) were administered to maintain blood pressure and heart rate within 20\% fluctuation after enough opioids. If the MAP was higher than 120 $\mathrm{mmHg}$ or lower than $60 \mathrm{mmHg}$, the HR was higher than $100 \mathrm{bpm}$ or lower than $50 \mathrm{bpm}$, the vasoactive drugs were also necessary for correcting the fluctuation. Intractable hypotension or bradycardia was recorded when hypotension or bradycardia recurred within 5 minutes of returning to normal range with vasoactive agents and continuous vasoactive agents were required to maintain normal MAP or HR. When intractable hypotension or bradycardia occurred, the test drug was stopped and vasoactive drugs or other necessary measures such as blood transfusion and rapid fluid infusion were used for improving the situation.

Maintenance of anesthesia was achieved with sevoflurane (2 4\% in $100 \%$ oxygen), and its concentration was adjusted based on BIS which was kept between 40 and 60 . Cis-atracurium $(0.1 \mathrm{mg} / \mathrm{kg} / \mathrm{h})$ was administered during maintenance at the discretion of the anesthesiologist. Decrease the anesthesia depth and use remifentanil 3-5 ug/ $\mathrm{kg} / \mathrm{h}$ (regulated according to MAP and HR) when a drainage tube was placed. All the patients were admitted to postanesthesia care unit (PACU) for at least half an hour after extubation until vitals are stable before being discharged to regular floor.

\section{Postoperative Analgesia}

All patients were provided with a patient-controlled analgesia (PCA) pump that delivered a mixture of sufentanil $1 \mu \mathrm{g} / \mathrm{kg}$, dexmedetomidine $1 \mu \mathrm{g} / \mathrm{kg}$, and palonosetron
$0.25 \mathrm{mg}$ to $150 \mathrm{~mL}$ at the basal rate $3 \mathrm{~mL} /$ hour, a $2 \mathrm{~mL}$ per demand dose with a lock-out time of 20 minutes. The PCA pump was started immediately after the operation upon arrival in the PACU. When the patient's numerical rating scale (NRS) $\geq 4$, a demand dose of the PCA pump was given to relieve the pain. And intravenous flurbiprofen axetil $50 \mathrm{mg}$ iv. and intramuscular pethidine $50 \mathrm{mg} \mathrm{im}$. were the first- and second-line treatments for breakthrough pain, respectively, for numerical rating scale (NRS) $\geq 4$ or at the patient's request. Breakthrough nausea and vomiting were managed with intravenous palonosetron at $0.25 \mathrm{mg}$ as needed.

\section{Measurement Index}

The mean arterial pressure (MAP) and heart rate (HR) were recorded at entering the room (T1), after loading dosage (T2), after anesthesia induction (T3), 1 min after intubation (T4), 5 min after skin cutting (T5), $1 \mathrm{~h}$ after skin cutting (T6), $2 \mathrm{~h}$ after skin cutting (T7) and $5 \mathrm{~min}$ after extubation (T8), respectively. Intubation response was considered to have occurred when MAP or HR at 5 minutes after intubation exceeds $15 \%$ or more than that at 5 minutes after induction of anesthesia (before intubation). At the same time, when the MAP or HR at 5 minutes after extubation was $15 \%$ or higher than that at 5 minutes before spontaneous breathing occurred before extubation, it was considered as extubation response. The incidences of intubation and extubation response were recorded separately. The NRS ( 0 for painless and 10 for maximum pain) was recorded 5 minutes, 30 minutes, $1 \mathrm{~h}, 4 \mathrm{~h}, 24 \mathrm{~h}$, and $48 \mathrm{~h}$ after operation.

The primary outcomes were the incidences of intubation and extubation response. The second outcomes were perioperative opioid consumption and pain scores, intraoperative hemodynamic, number of postoperative rescue analgesic usage, frequency of adverse events such as nausea, vomiting, refractory hypotension and bradycardia.

\section{Sample Size Calculation and Randomization}

The sample size was calculated based on a $30 \%$ expected difference in intubation and extubation responses based on previous study ${ }^{12}$ and our pre-trial. For a study power of $80 \%$ $(\alpha=0.05, \beta=0.2$ ), the total sample size was 114 with 38 patients in each group (PASS 15.0; NCSS Statistical Software, Kaysville, Utah). Assuming a presumably dropout rate of $20 \%$ (including loss to follow-up and cessation of the test due to severe hemodynamic instability), the final sample 


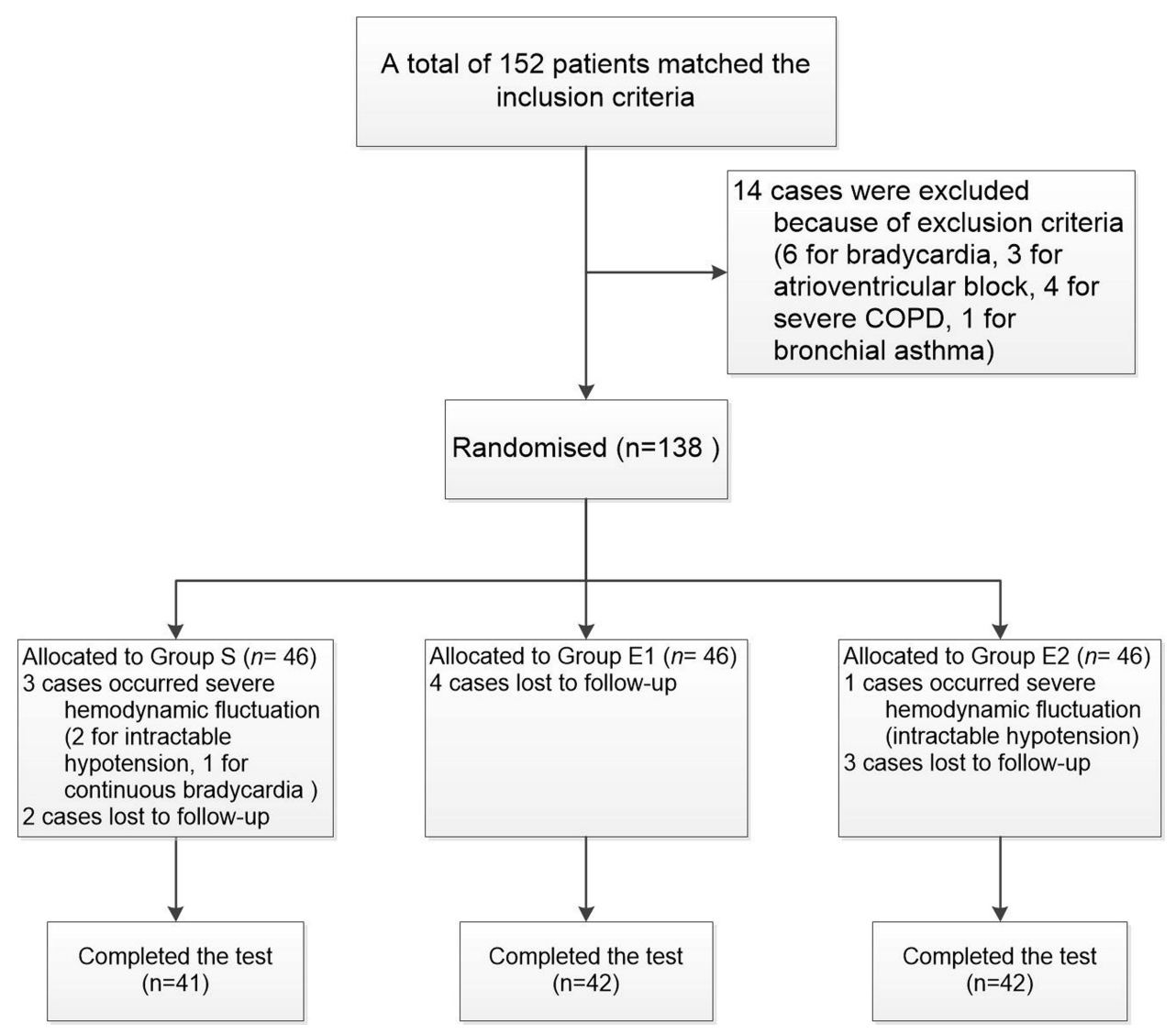

Figure I Flow chart of inclusion, exclusion, and randomization of all patients.

size was determined as total 138 (with 46 patients in each group). We applied the Visual Binning function of Statistical Program for Social Sciences (SPSS) to randomly divide 138 patients into three groups (33.33\% for each group). The grouped results were wrapped in opaque envelopes. The anesthesiologists responsible for data collection did not know the grouped results until the day of surgery.

\section{Statistical Analysis}

Statistical Program for Social Sciences (SPSS) was used for statistical analysis of the collected data. For scale (quantitative data), such as age, BMI, opioid dosage, MAP, HR, we statistically described them in the form of mean \pm standard deviation, and used Kolmogorov-Smirnov to test their normal distribution and applied analysis of variance (ANOVA) to test them. If the significance (P value) $<0.05$, then the data were analyzed by the least significant difference (LSD) test. For nominal (qualitative data), such as gender, intubation response, extubation response, we used frequency (percentage) to describe them statistically and applied the Chisquare test to verify its significance. If $\mathrm{P}$ value $<0.05$, then proceeded Chi-square test between each two groups. For ordinal (grade data), such as NRS, we used median (range) for statistical description. Kruskal-Wallis test was used to compare the overall differences, and the Wilcoxon test was applied to further analysis if $\mathrm{P}$ value $<0.05$. All test results determined that $\mathrm{P}$ value $<0.05$ was statistically significant.

\section{Results}

There were totally 125 patients completed the test (Figure 1).

\section{Basic Information and Intraoperative General Conditions}

In the statistical analysis of the patients' basic information and general conditions during operation, it was found that there were no statistical differences ( $P>0.05$; Table 1).

\section{Perioperative Hemodynamics}

In the statistical analysis of the MAP and $\mathrm{HR}$, there was a significant difference in $\mathrm{MAP}_{\mathrm{T} 4}, \mathrm{HR}_{\mathrm{T} 2}, \mathrm{HR}_{\mathrm{T} 5}, \mathrm{HR}_{\mathrm{T} 6}$, and $\mathrm{HR}_{\mathrm{T} 8}$ among the three groups $(\mathrm{P}<0.05$, Figure 2$)$, while there was no statistical difference between Group $\mathrm{E}_{1}$ and Group $\mathrm{E}_{2}\left(\mathrm{P}>0.05\right.$, Figure 2). The $\mathrm{MAP}_{\mathrm{T} 8}$ of Group $\mathrm{E}_{2}$ 
Table I Basic Information and Intraoperative General Conditions

\begin{tabular}{|c|c|c|c|c|}
\hline & Group $S(N=4 I)$ & Group $E_{1}(N=42)$ & Group $E_{2}(N=42)$ & $P$ value \\
\hline Age, years & $56.88 \pm 8.889$ & $56.24 \pm 8.864$ & $55.95 \pm 12.778$ & 0.917 \\
\hline Sex, M/F, N (\%) & $25(60.98) / 16(39.02)$ & $24(57.14) / 18(42.86)$ & $28(66.67) / 14(33.33)$ & 0.665 \\
\hline Body height, $\mathrm{cm}$ & $170.02 \pm 8.909$ & $168.50 \pm 7.372$ & $168.36 \pm 7.567$ & 0.575 \\
\hline Body weight, kg & $70.96 \pm 10.639$ & $66.83 \pm 9.067$ & $67.89 \pm 10.318$ & 0.155 \\
\hline $\mathrm{BMI}, \mathrm{kg} / \mathrm{m}^{2}$ & $24.18 \pm 2.473$ & $23.56 \pm 2.215$ & $23.90 \pm 2.607$ & 0.515 \\
\hline ASA, II/III, N (\%) & I5 (36.59)/26 (63.4I) & $21(50.00) / 21(50.00)$ & $17(40.48) / 25$ (59.52) & 0.444 \\
\hline Hypertension, N (\%) & $10(24.39)$ & $6(14.29)$ & $10(23.81)$ & 0.442 \\
\hline Laparoscopic surgery, N (\%) & $27(65.85)$ & $25(59.52)$ & $25(59.52)$ & 0.792 \\
\hline Duration of surgery, min & $212.80 \pm 26.126$ & $222.62 \pm 32.931$ & $210.00 \pm 36.759$ & 0.175 \\
\hline Transfusion volume, mL & $2385.37 \pm 40 \mathrm{I} .597$ & $2447.62 \pm 441.305$ & $2390.48 \pm 496.726$ & 0.781 \\
\hline Blood transfusion, $\mathrm{N}(\%)$ & $14(34.15)$ & $17(40.48)$ & $21(50.00)$ & 0.336 \\
\hline Urine volume, $\mathrm{mL}$ & $606.10 \pm 195.638$ & $555.95 \pm 190.059$ & $557.14 \pm 231.793$ & 0.455 \\
\hline
\end{tabular}

Notes: Scale variables are described in the form of mean \pm standard deviation and nominal variables are in form of frequency (percentage). No statistical significance is found $(P>0.05)$.

Abbreviations: BMI, Body Mass Index; ASA, American Society of Anesthesiologists.

were significantly lower than the other two groups $(\mathrm{P}<$ 0.05 , Figure 2). The number of intubation responses in Group $\mathrm{S}$ was higher than that in the other two groups $(\mathrm{P}<$ 0.05 , Table 2). While the incidence of extubation response in Group $\mathrm{E}_{2}$ was significantly less than Group $\mathrm{S}$ and Group $\mathrm{E}_{1}(\mathrm{P}<0.05$, Table 2$)$. In the use of vasoactive drugs, only nitroglycerin in Group $\mathrm{S}$ was significantly more than that in Group $E_{1}$ and Group $E_{2}(P<0.05$, Table 2).

\section{Analgesia and Adverse Reactions}

In the use of analgesic drugs, the amount of intraoperative opioids in Group $\mathrm{E}_{1}$ and Group $\mathrm{E}_{2}$ was significantly less than that in Group $\mathrm{S}(\mathrm{P}<0.05$, Table 3), while there was no significant difference between the two groups $(\mathrm{P}>$ 0.05 , Table 3). Also, no statistical difference was showed in the amount of opioids and NRS within 48 hours after surgery among the three groups $(\mathrm{P}>0.05$, Table 3 , Figure 3). The comparison of the incidence of adverse reactions among the three groups found no statistical difference $(P>0.05$, Table 3).

\section{Discussion}

From the results of this randomized controlled trial, it can be seen that the continuous administration of esmolol in the perioperative period has a positive impact on the stability of hemodynamics. Before anesthesia induction, esmolol $0.5 \mathrm{mg} / \mathrm{kg}$ (Group $\mathrm{E}_{1}$ ) and $1.0 \mathrm{mg} / \mathrm{kg}$ (Group $\mathrm{E}_{2}$ ) infusion can significantly reduce the incidence of intubation response without increasing the risk of hypotension. The dose of esmolol used in this study is lower than that of previous studies. ${ }^{13,14}$ Through the comparison of several studies, we believe that a low dose of esmolol could already significantly improve the increase in blood pressure caused by intubation. The main reason is that enough analgesics are given in anesthesia induction, and propofol itself has an antihypertensive effect, so combining with

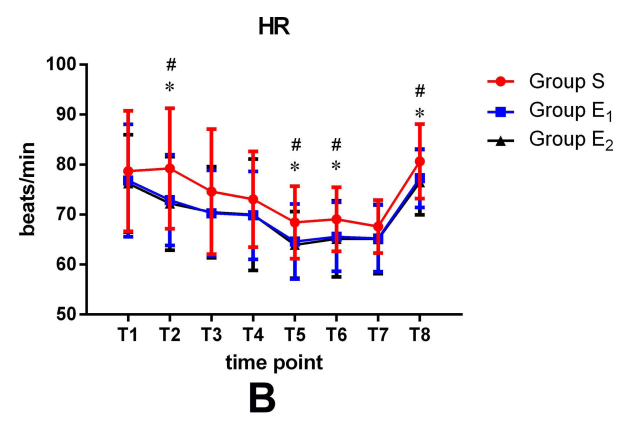

Figure 2 Changes in MAP $(\mathbf{A})$ and $\mathrm{HR}(\mathbf{B})$ among the three groups; scale variables presented as mean \pm standard deviation; *P $<0.05$ between Group $\mathrm{S}$ and Group $\mathrm{E}_{1}$; ${ }^{\#} \mathrm{P}<$ 0.05 between Group $S$ and Group $E_{2}$.

Abbreviations: MAP, mean arterial pressure; HR, heart rate. 
Table 2 Hemodynamic Fluctuation and Vasoactive Drugs

\begin{tabular}{|c|c|c|c|c|}
\hline & $\begin{array}{l}\text { Group } S \\
(N=4 I)\end{array}$ & $\begin{array}{l}\text { Group } E_{1} \\
(N=42)\end{array}$ & $\begin{array}{l}\text { Group } E_{2} \\
(N=42)\end{array}$ & $P$ values $\left(\mathbf{P}_{\text {GroupS\&EI }} / \mathbf{P}_{\text {GroupS\&E2 }} / \mathbf{P}_{\text {GroupE I\&E2 }}\right)$ \\
\hline Intubation response, $\mathrm{N}(\%)$ & $23(56.10)$ & II (26.19) & $8(19.05)$ & $0.020 * *\left(0.007 * / 0.00 I^{\#} / 0.603\right)$ \\
\hline Extubation response, $\mathrm{N}(\%)$ & $31(75.61)$ & $27(64.29)$ & $19(45.24)$ & $0.016^{* *}\left(0.340 / 0.007^{\#} / 0.124\right)$ \\
\hline Ephedrine, mg & $1.05 \pm 2.024$ & $0.74 \pm 1.624$ & $1.00 \pm 1.887$ & 0.712 \\
\hline Phenylephrine, ug & $1.71 \pm 6.286$ & $0.48 \pm 3.086$ & $2.86 \pm 9.183$ & 0.266 \\
\hline Nitroglycerin, ug & $106.10 \pm 205.607$ & $34.52 \pm 69.395$ & $36.90 \pm 105.379$ & $0.032 * *\left(0.020 * / 0.025^{\#} / 0.937\right)$ \\
\hline Urapidil, mg & $0.91 \pm 4.321$ & $0.00 \pm 0.000$ & $0.89 \pm 3.258$ & 0.312 \\
\hline Atropine, ug & $17.07 \pm 62.859$ & $7.14 \pm 46.291$ & $36.90 \pm 105.379$ & 0.631 \\
\hline Isoprenaline, ug & $0.00 \pm 0.000$ & $0.00 \pm 0.000$ & $0.00 \pm 0.000$ & I \\
\hline
\end{tabular}

Notes: Nominal used frequency (percentage) and scale used mean \pm standard deviation to describe; **P $<0.05$ among three groups; *P $<0.05$ between Group $\mathrm{S}$ and Group $\mathrm{E}_{1} ;{ }^{\#} \mathrm{P}<0.05$ between Group $\mathrm{S}$ and Group $\mathrm{E}_{2}$.

Table 3 Opioids Dosage and Side Effects

\begin{tabular}{|c|c|c|c|c|}
\hline & $\begin{array}{l}\text { Group S } \\
(N=4 I)\end{array}$ & $\begin{array}{l}\text { Group } E_{1} \\
(N=42)\end{array}$ & $\begin{array}{l}\text { Group } E_{2} \\
(N=42)\end{array}$ & $\begin{array}{l}\mathbf{P}_{\text {values }}\left(\mathbf{P}_{\text {GroupS\&E1 }} / \mathbf{P}_{\text {GroupS\&E2 }}\right. \\
\left.\text { / } \mathbf{P}_{\text {GroupEI\&E2 }}\right)\end{array}$ \\
\hline Dosage of intraoperative opioids, MME & $30.74 \pm 6.089$ & $28.15 \pm 4.347$ & $27.74 \pm 4.429$ & $0.015^{* *}\left(0.020 * / 0.007^{\#} / 0.704\right)$ \\
\hline Dosage of postoperative opioids (0-4h), MME & $3.37 \pm 0.446$ & $3.28 \pm 0.410$ & $3.24 \pm 0.467$ & 0.417 \\
\hline Dosage of postoperative opioids (0-24h), MME & $17.83 \pm 0.459$ & $|7.7| \pm 0.425$ & $17.74 \pm 0.530$ & 0.531 \\
\hline Dosage of postoperative opioids (0-48h), MME & $29.72 \pm 0.853$ & $29.47 \pm 0.826$ & $29.4 I \pm 0.615$ & 0.149 \\
\hline Needed rescue analgesia, $\mathrm{N}(\%)$ & $4(9.76)$ & $6(14.29)$ & $3(7.14)$ & 0.585 \\
\hline PONV, N(\%) & II (26.83) & $6(14.29)$ & $9(21.43)$ & 0.368 \\
\hline Refractory hypotension or bradycardia, N (\%) & $0(0.00)$ & I (2.38) & $2(4.76)$ & 0.772 \\
\hline
\end{tabular}

Notes: Scale variables are described in the form of mean \pm standard deviation and nominal variables are in form of frequency (percentage). $* * P<0.05$ among three groups; *P $<0.05$ between Group S and Group EI; ${ }^{*} \mathrm{P}<0.05$ between Group S and Group E2. Refractory hypotension or bradycardia means hypotension and bradycardia requiring continuous use of vasoactive drugs.

Abbreviations: MME, metabolic morphine equivalent; PCIA, patient-controlled intravenous analgesia; PONV, postoperative nausea and vomiting.

a small amount of esmolol can inhibit intubation response. In previous studies, most of them are about the influence of single-dose of esmolol on extubation response, ${ }^{15,16}$ while articles of the effect of continuous esmolol administration during the operation on extubation are little. Our

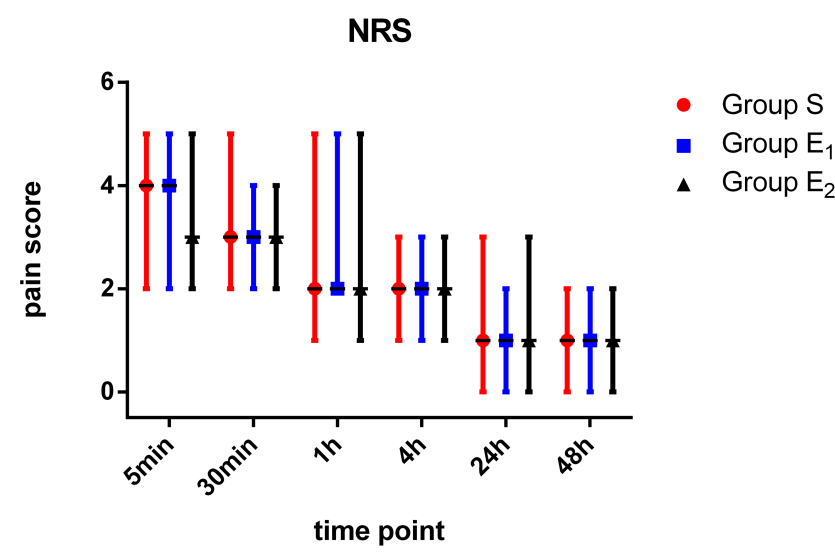

Figure 3 NRS changes among three groups; ordinal variables described as median (range). No statistical significance is found $(P>0.05)$.

Abbreviation: NRS, numerical rating scale. trial indicates that continuous infusion of esmolol $2.0 \mathrm{mg} /$ $\mathrm{kg} / \mathrm{h}$ can inhibit the extubation response, while esmolol administration of $0.5 \mathrm{mg} / \mathrm{kg} / \mathrm{h}$ can only stabilize the HR after extubation without affecting MAP, so it cannot reduce the occurrence of extubation response. What is more, infusion of esmolol $2.0 \mathrm{mg} / \mathrm{kg} / \mathrm{h}$ cannot completely inhibit extubation response. It is probably a consequence of the weakening or disappearance of anesthetic effect, together with the pain of surgical wound and the stimulation of extubation on trachea. Therefore, it is difficult to inhibit the extubation response completely caused by various reasons by using esmolol simply.

In our study, we find that continuous administration of esmolol during the operation can inhibit the remarkable increase of blood pressure during intubation, skin incision, extubation (only with continuous infusion of esmolol $2.0 \mathrm{mg} / \mathrm{kg} / \mathrm{h}$ ) and can promote the heart rate to maintain a lower level in the relatively stable stage of operation. On the one hand, it can cut down the increase of cardiac afterload and work caused by increased blood pressure. 
On the other hand, lower heart rate can reduce myocardial oxygen consumption, thus reducing the occurrence of cardiovascular accidents. A meta-analysis showed that esmolol seems to be beneficial for the prevention of perioperative myocardial ischaemia. ${ }^{17}$ Another study proved that esmolol $0.5 \mathrm{mg} / \mathrm{kg}$ combined with nicardipine $20 \mathrm{ug} / \mathrm{kg}$ during rapid-sequence induction can effectively reduce cardiovascular response. ${ }^{18}$ Esmolol can also be used for controlled hypotension in various operations such as functional endoscopic sinus surgery (FESS), tympanoplasty and laparoscopic surgeries. ${ }^{19-21}$ These studies have shown that esmolol has a positive effect on the maintenance of intraoperative hemodynamic stability.

In addition, we find that esmolol can reduce intraoperative opioids dosage, which is consistent with the previous results of Hamed et al. ${ }^{22}$ What is more, it has also been proved that intraoperative infusion of esmolol can reduce postoperative opioid dosage in Gelineau study. $^{23}$ Esmolol itself has no analgesic effect, but some studies consider that its auxiliary analgesic effect is achieved through extending the effect of opioids. ${ }^{24}$ In this study, different doses of esmolol do not affect the dosage of postoperative analgesic drugs. It may be that all patients in this trial took QLB before surgery, which is a new trunk block method based on the transverse abdominis plane block (TAPB). Blanco et al showed that QLB was closer to the axon and sympathetic trunk, which had more obvious advantages in the duration of trunk analgesia and the weakening of visceral pain than TAPB. ${ }^{25}$ The doses of postoperative opioids in the three group are all obviously reduced. As a result, it is difficult to find their statistical significance. What is more, we do not use esmolol continuously after extubation so that we cannot find the persistent influence of esmolol on postoperative analgesia.

In the analysis of postoperative adverse reactions, it is found that esmolol does not increase the incidence of postoperative nausea and vomiting (PONV), persistent hypotension and bradycardia, which benefited from the ultra-short effect of esmolol. ${ }^{26}$ Some other studies have shown that esmolol can reduce $\mathrm{PONV}^{27}$ which is mostly achieved by reducing the amount of postoperative opioids.

This trial has the following limitations in the design process. Firstly, the quadratus lumborum block was performed after anesthesia induction. Although the anesthesiologist used the same approach, we did not judge the range and effect of QLB which might influence the study results. Secondly, this study did not collect the time of first flatus and defecation, so that there was no theoretical basis for the effect of esmolol on the recovery of postoperative gastrointestinal function. Thirdly, we only selected one time point after intubation and extubation for MAP and HR statistics, which may obscure reliable estimates of the true incidence of intubation and extubation reactions. Finally, this study only compared the MAP and HR at the same time point, but did not compare the hemodynamic fluctuation of patients in a short time, and MAP and HR monitoring every 5 minutes may be a better approach.

\section{Conclusions}

Esmolol $0.5 \mathrm{mg} / \mathrm{kg}$ or $1.0 \mathrm{mg} / \mathrm{kg}$ short-term infusion can effectively inhibit the intubation response, while only continuous infusion of esmolol $2.0 \mathrm{mg} / \mathrm{kg} / \mathrm{h}$ intraoperatively was safe and effectively to reduce the occurrence of extubation response. Both $0.5 \mathrm{mg} / \mathrm{kg} / \mathrm{h}$ and $2.0 \mathrm{mg} / \mathrm{kg} / \mathrm{h}$ continuous infusion of esmolol can reduce the dosage of intraoperative opioids without increasing the risk of adverse reactions.

\section{Abbreviations}

ANOVA, analysis of variance; ASA, American Society of Anesthesiologists; BMI, body mass index; COPD, chronic obstructive pulmonary disease; ERAS, enhanced recovery after surgery; FESS, functional endoscopic sinus surgery; HPA(HTPA), hypothalamic-pituitary-adrenal; HR, heart rate; LSD, least significant difference; MAP, mean arterial pressure; NCSS, number crunching statistical system; NRS, numerical rating scale; PACU, postanesthesia care unit; PASS, power analysis and sample size; PCA, patientcontrolled analgesia; PONV, post-operative nausea and vomiting; QLB, quadratus lumborum block; SPSS, statistical program for social sciences; TAPB, abdominis plane block; US-QLB, ultrasound-guided quadratus lumborum block.

\section{Data Sharing Statement}

All data generated or analyzed during this study were included in this published article. Further inquiries can be directed to Professor Xin Zhao on reasonable request.

\section{Ethics Approval and Consent to Participate}

This study was approved by the Ethics Committee of the Second Hospital of Shandong University with the approval 
number KYLL-2019(LW)009 on June 10, 2019, and in accordance with the 1964 Helsinki declaration and its later amendments or comparable ethical standards. The study was prospectively registered at http://www.chictr.org.cn on July 15, 2019, identifier ChiCTR1900024538. Informed consent was obtained from all of the participants.

\section{Consent for Publication}

All authors have read the manuscript, attest to the validity and legitimacy of the data and its interpretation, and agree to its publication.

\section{Acknowledgments}

The authors gratefully thank Santosh Kumar Paidi from Johns Hopkins University, USA, for useful comments, suggestions and language editing for improving the manuscript. Chao Zheng acknowledges support from the Taishan Scholars Program of Shandong Province (tsqn201812135). We would like to thank all participants involved in the study for their cooperation.

\section{Disclosure}

The authors declare that they have no competing interests.

\section{References}

1. Yaribeygi H, Panahi Y, Sahraei H, Johnston TP, Sahebkar A. The impact of stress on body function: a review. EXCLI J. 2017;16:1057-1072. doi:10.17179/excli2017-480

2. Saito H. [Endocrine response to surgical stress]. Nihon Geka Gakkai Zasshi. 1996;97(9):701-707. Japanese.

3. Müller-Lissner S, Bassotti G, Coffin B, et al. Opioid-induced constipation and bowel dysfunction: a clinical guideline. Pain Med. 2017;18 (10):1837-1863.

4. Colvin LA, Bull F, Hales TG. Perioperative opioid analgesia-when is enough too much? A review of opioid-induced tolerance and hyperalgesia. Lancet (London, England). 2019;393 (10180):1558-1568. doi:10.1016/S0140-6736(19)30430-1

5. Lavand'homme P, Steyaert A. Opioid-free anesthesia opioid side effects: tolerance and hyperalgesia. Best Pract Res Clin Anaesthesiol. 2017;31(4):487-498. doi:10.1016/j.bpa.2017.05.003

6. Wiest DB, Haney JS. Clinical pharmacokinetics and therapeutic efficacy of esmolol. Clin Pharmacokinet. 2012;51(6):347-356. doi:10.2165/11631590-000000000-00000

7. Harless M, Depp C, Collins S, Hewer I. Role of esmolol in perioperative analgesia and anesthesia: a literature review. AANA J. 2015;83 (3):167-177.

8. Hwang WJ, Moon YE, Cho SJ, Lee J. The effect of a continuous infusion of low-dose esmolol on the requirement for remifentanil during laparoscopic gynecologic surgery. J Clin Anesth. 2013;25 (1):36-41. doi:10.1016/j.jclinane.2012.06.005

9. Morais VBD, Sakata RK, Huang APS, Ferraro L. Randomized, double-blind, placebo-controlled study of the analgesic effect of intraoperative esmolol for laparoscopic gastroplasty. Acta Cir Bras. 2020;35(4):e202000408. doi:10.1590/s0102-865020200040000008
10. Watts R, Thiruvenkatarajan V, Calvert M, Newcombe G, van Wijk RM. The effect of perioperative esmolol on early postoperative pain: a systematic review and meta-analysis. J Anaesthesiol Clin Pharmacol. 2017;33(1):28-39. doi:10.4103/0970-9185.202182

11. Figueredo E, Garcia-Fuentes EM. Assessment of the efficacy of esmolol on the haemodynamic changes induced by laryngoscopy and tracheal intubation: a meta-analysis. Acta Anaesthesiol Scand. 2001;45(8):1011-1022. doi:10.1034/j.1399-6576.2001.450815.x

12. Ratnani E, Sanjeev OP, Singh A, Tripathi M, Chourasia HK. A comparative study of intravenous esmolol, labetalol and lignocaine in low doses for attenuation of sympathomimetic responses to laryngoscopy and endotracheal intubation. Anesth Essays Res. 2017;11 (3):745-750. doi:10.4103/aer.AER_9_17

13. Mulimani SM, Talikoti DG, Vastrad VV, Sorganvi VM. Efficacy of a bolus dose of esmolol and bolus dose of lignocaine for attenuating the pressor response to laryngoscopy and endotracheal intubation in general anesthesia: a comparative study. Anesth Essays Res. 2019;13 (2):292-296. doi:10.4103/aer.AER 3119

14. Gupta S, Tank P. A comparative study of efficacy of esmolol and fentanyl for pressure attenuation during laryngoscopy and endotracheal intubation. Saudi J Anaesth. 2011;5(1):2-8. doi:10.4103/1658$354 X .76473$

15. Arar C, Colak A, Alagol A, et al. The use of esmolol and magnesium to prevent haemodynamic responses to extubation after coronary artery grafting. Eur $J$ Anaesthesiol. 2007;24(10):826-831. doi:10.1017/S0265021507000865

16. Prajwal Patel HS, Shashank MR, Shivaramu BT. Attenuation of hemodynamic response to tracheal extubation: a comparative study between esmolol and labetalol. Anesth Essays Res. 2018;12 (1):180-185. doi:10.4103/aer.AER_130_17

17. Ollila A, Vikatmaa L, Sund R, Pettilä V, Wilkman E. Efficacy and safety of intravenous esmolol for cardiac protection in non-cardiac surgery. A systematic review and meta-analysis. Ann Med. 2019;51 (1):17-27. doi:10.1080/07853890.2018.1538565

18. Moon YE, Lee SH, Lee J. The optimal dose of esmolol and nicardipine for maintaining cardiovascular stability during rapid-sequence induction. J Clin Anesth. 2012;24(1):8-13. doi:10.1016/j.jclinane.2010.12.010

19. Gökahmetoğlu G, Pehlivan S, Aksu R, Biçer C. Effects of dexmedetomidine and esmolol on otoacoustic emissions during controlled hypotensive anesthesia: randomized clinical trial. Clin Invest Med. 2020;43(1):E9-e17. doi:10.25011/cim.v43i1.33564

20. Bajwa SJ, Kaur J, Kulshrestha A, Haldar R, Sethi R, Singh A. Nitroglycerine, esmolol and dexmedetomidine for induced hypotension during functional endoscopic sinus surgery: a comparative evaluation. J Anaesthesiol Clin Pharmacol. 2016;32(2):192-197. doi:10.4103/0970-9185.173325

21. Verma A, Srivastava D, Paul M, Chatterjee A, Chandra A. Effect of esmolol and diltiazem infusions on hemodynamic response to pneumoperitoneum on laparoscopic simple nephrectomy: a randomized controlled trial. Anesth Essays Res. 2018;12(1):85-91. doi:10.4103/ aer.AER_203_17

22. Hamed JME, Ataalla WM. Esmolol infusion reduces blood loss and opiate consumption during fertility preserving myomectomy. Anesth Essays Res. 2019;13(3):423-429. doi:10.4103/aer. AER 11819

23. Gelineau AM, King MR, Ladha KS, Burns SM, Houle T, Anderson TA. Intraoperative esmolol as an adjunct for perioperative opioid and postoperative pain reduction: a systematic review, meta-analysis, and meta-regression. Anesth Analg. 2018;126 (3):1035-1049. doi:10.1213/ANE.0000000000002469

24. Bahr MP, Williams BA. Esmolol, antinociception, and its potential opioid-sparing role in routine anesthesia care. Reg Anesth Pain Med. 2018;43(8):815-818. doi:10.1097/AAP.0000000000000873 
25. Blanco R, Ansari T, Riad W, Shetty N. Quadratus lumborum block versus transversus abdominis plane block for postoperative pain after cesarean delivery: a randomized controlled trial. Reg Anesth Pain Med. 2016;41(6):757-762. doi:10.1097/ AAP.0000000000000495

26. Muller MD, Ahmad TA, Vargas Pelaez AF, et al. Esmolol infusion versus propranolol infusion: effects on heart rate and blood pressure in healthy volunteers. $J$ Appl Physiol. 2017;122(3):511-519. doi:10.1152/japplphysiol.00940.2016
27. Lee SJ, Lee JN. The effect of perioperative esmolol infusion on the postoperative nausea, vomiting and pain after laparoscopic appendectomy. Korean J Anesthesiol. 2010;59(3):179-184. doi:10.4097/kjae.2010.59.3.179

\section{Publish your work in this journal}

Drug Design, Development and Therapy is an international, peerreviewed open-access journal that spans the spectrum of drug design and development through to clinical applications. Clinical outcomes, patient safety, and programs for the development and effective, safe, and sustained use of medicines are a feature of the journal, which has also been accepted for indexing on PubMed Central. The manuscript management system is completely online and includes a very quick and fair peer-review system, which is all easy to use. Visit http://www. dovepress.com/testimonials.php to read real quotes from published authors.

Submit your manuscript here: https://www.dovepress.com/drug-design-development-and-therapy-journal 